\title{
Basic Quality Education; The Importance of Integrating Different Approaches for
}

\author{
Quality Pre-School Education in Pakistan \\ * Dr. Waqar Un Nisa Faizi, Assistant Professor \\ ** Dr. Anila Fatima Shakil, Associate Professor \\ *** Ms. Fozia Bashir, M.Phil (Corresponding Author)
}

\begin{abstract}
Quality education is one of the key indicators for economic development of a country. Consequently, most developing countries have committed themselves in several international forums not only to provide education but also to make it a basic right for everyone. So far, several developing countries have managed to make giant leaps towards this direction. For instance, provision of basic education has been made free and compulsory in countries like Pakistan and Kenya beside other countries. The purpose of this research paper is to analyze the different approaches used in teaching preschoolers in developing countries and to understand how to improve the quality of education through integrating those approaches.it relies on qualitative research method and is basically based on secondary data. The focus of this research is on different methods or approaches used in teaching preschoolers, their effectiveness, and that of an integrated system or approach. It discovered that integrating the different approaches leads to a better-quality education as compared to using each approach separately.
\end{abstract}

Keywords: Quality Education, Approaches, Pre-school Education

Introduction

Quality education is one of the main pillars of growth and development of a country's economy. The importance of quality education has been echoed for over six decades from the time when the United Declaration of Human Rights (UDHR) first declared quality primary education as a basic right for all people. To date, almost every developing country globally either has attained or is close towards achieving the universal primary education goal. For instance, Pakistan has managed to make education free and compulsory for children aged between 3 to 16 years. From the time this decision was made and framed into law, Pakistan's education sector has reported an increase in the number of children enrolled in preschool and primary school at large. Additionally, the literacy levels in Pakistan have increased considerably over the past few years.

While this improvement is good news for Pakistan's economic growth, there is much concern arising from the quality aspects of the education on offer. Some of the issues raised include; teacherpupil ratio, the provision of studying materials, and syllabus change, among others. However, the most important yet often ignored issue is the emphasis of quality in preschool education. At this stage, children get exposure to basic languages skills, attitudes, social habits, concepts, skills, and knowledge needed for formal learning. What a child is taught at this stage has a lasting impact on the wellbeing of an individual, thus the need for quality education. Currently, there are different approaches to pre-school teaching that are intended to enable preschoolers to make the most out of their learning experiences. Therefore, the question for parents and educators is; do children gain a better experience by learning through one approach or could they benefit more by integrating the different approaches for quality pre-school education?

There are many approaches or philosophies, applied in teaching pre-school children. The most commonly used are: Montessori, Waldorf, Reggio Emilia, High Scope, Bank Street, and parent Co-ops approaches uses different strategies in ensuring that children get the best learning outcomes. Even so, the objective that links these approaches together is the urge to impart a relatively permanent

* Department of Education, Islamia College Peshawar Email: faizi@icp.edu.pk

** Department of Education, Jinnah University for Women Karachi

*** Department of Education and Psychology, Kohat University of Science and Technology, Kohat Email: farsomal@yahoo.com 
change in behavior because of experience, instruction, observation, and practice (Sanders \& Rivers, 1996).

\section{Research Questions}

The following are the research questions for the study

1. Which Method is the most effective one or teaching preschoolers?

2. What is the most common method used in teaching preschoolers?

3. How will an integrated approach be applied perform?

4. What main factors are to be considered for quality preschool education?

\section{Approaches Used}

The Montessori approach takes a developmental approach to learning. Maria Montessori, an educator and physician, developed the approach. In this program, every teacher is required to have an undergraduate or graduate degree in or for early childhood education and a Montessori Certification. This program emphasizes hands-on learning, exploration of nature and creativity accompanied by gentle guidance from teachers. The approach seeks to develop the character, senses, academic ability, and the practical life skills of the child. The Waldorf approach developed from the works of the Australian writer Rudolf Steiner. According to Waldorf, a child learns best when there is nurturing of his or her interests, body, spirit and soul. In Waldorf pre-schools, a child learns through creative activities, rhythmic repetition, and hands-on learning activities. The approach also seeks to offer a supportive environment whereby children can develop their talents and imitate abilities as well as strong inner enthusiasm that is a key ingredient in learning (Smith, 1980).

Reggio Emilia is one of the other approaches used. It was formed in the 1940s in Italy. Today, many schools globally embrace this approach. The children are encouraged to learn through projects, art, and activities that mirror their interests and ideas. In addition to this, there is an emphasis on the need for exploring the environment, self-expression, and the significance of the community. Even so, the Reggio Emilia approach does not have a well-developed system of credentialing, curriculum, or teacher training. The approach has only remained to be an educational practice and theory. Nevertheless, it is still relevant and practiced in many pre-schools worldwide (Smith, 1980).

The other common approach used in pre-school education is the Bank Street philosophy developed by John Dewey. The approach puts much emphasis on the child's cognitive, emotional, social, and physical development. Additionally, tutors teach children mainly through experience and are encouraged to be an active learner. The other dimension to this approach is that teachers mostly play the role of a guide while expecting children to set their learning pace. In addition to this way of doing things, tutors teach using practical activities such as puzzles, modeling, dramatic plays, and building blocks (Morrison, 1998).

The High Scope approach is another program in which preschoolers learn through participatory learning. In this form of learning, the tutor engages preschoolers consistently using daily routines in well-arranged classrooms. This program also engages children in activities that enable them to interact with their surroundings practically (Pianta et al., 2005). Finally yet importantly, parent's co-operative strategy is another approach that is used to help in educating preschoolers. In this program, parents co-operate with teachers by working together on a daily basis to help in teaching the children. The focus in this approach is helping the preschoolers to learn co-operation and resolve conflict. Besides learning with their children, parents also involve themselves actively in the management of these particular schools (Smith, 1980).

The Montessori pre-school program is the most popular approach among all the approaches, and it has been in existence for over a hundred years. The approach recognizes that children have different interests and each child learns at his or her level and pace. Therefore, tutors neither push forward nor hold back the children in this program. The Montessori system also allows learners to know how to concentrate and focus. The two core ingredients in setting a good quality foundation for children's schooling is concentration and focus (Solomon, 1987). This approach addresses these needs by offering well-structured lessons that do not allow any interruptions during the learning process. (Muttock, 2002). For example, the approach ensures that there is concentration and focus of the child because the teacher does not move on to the next lesson until a child master's one's own concept properly.

The other benefit of this approach that it gives room for all learning skills styles. It is vital especially because children use different styles to learn. Children learn through listening, seeing, 
feeling, and movement of the body or through blending all these aspects (Czerwinski, 2007). Teachers at Montessori programs are skilled at applying all the body senses in conjunction with didactic materials when teaching children. Therefore, it is possible to accommodate children with different learning capabilities can fit in a Montessori program.

Montessori programmes enable learners to achieve competence, high levels of self-esteem and cooperation (Lore, 2002). Children learn these skills because tutors take them through practical lessons. Also, the Montessori classrooms are organized in such a way that children can easily access anything without asking for from other people. Moreover, in Montessori preschool, tutors allow children to choose the work that they want to do. Practical tools used such as brooms and mops are made in small sizes that children can handle with ease to encourage them to learn to work independently. In addition, the director of the school vigilantly monitors the children's progress as well as making sure that children are taken through the learning process at their rates. This approach seeks to motivate the personal interests of a child while at the same time giving his/ her an opportunity to explore the environment on their own. The idea behind the well-organized classrooms is to guide children in exploring and expressing themselves. These skills eventually help them to master self-direction that is crucial in the learning process.

The aim of the Montessori approach is to prepare the children for adulthood from their early years. Therefore, in Montessori classrooms, tutors treat children with dignity and respect. Whenever children fail to do things correctly, the approach helps them to find the solutions instead of criticizing them. Also, children in such classes are taught on the need to respect the rights of others. This culture in conjunction with the high self-esteem helps in raising a well-rounded and positive individual who will also be able to cope in a better while facing challenges. Lastly, the Montessori programme embraces a multidisciplinary angle that focuses on the interest of the learner. For instance, if a child is interested in things such as horses or cars, he or she would be encouraged to read about them so as to acquire language skills. The child is also encouraged to study the measurement of such objects or pictures, drawing them and even some aspects of those objects like geography and history. By doing so, a child's interest in studying subjects he/ she is not interested in, is picked. This approach leads to better, fast and fun way of learning new concepts.

The Waldorf program's approach is based on a holistic viewpoint. The learners who get education through this system are nurtured in a way that encourages them to view learning as an exciting opportunity (Moll, 2005). Accordingly, to prepare children for this form of learning, the Waldorf endeavors to harmonize the raw human needs of the body, spirit, and soul. Therefore, children who undergo this system experience real quality learning as they are more enthusiastic and often, they discover their interests early in life. The Waldorf approach also motivates children to learn easily by engaging them in repetitive activities. Therefore, in time, every learner catches up with the rest. Moreover, it fosters a sense of high self-esteem.

The Reggio Emilia philosophy has been in practice for over 70 years since its formation in 1940's. Learners in the Reggio Emilia schools benefit because they are encouraged to express themselves freely. Moreover, there is sensitization on the importance of the community. According to Wellman (1998), allowing children to speak freely help them to bring out the hidden talents, ideas, and interests that would otherwise remain suppressed of the opposite happened. In addition, children learn through philosophy are also able to identify their interests' way early. Such discovery is made possible because the philosophy encourages children to do activities and art projects that are indicative of their ideas and interests. The other aspect of Reggio Emilia approach is that it fosters cooperation in all areas of schooling. For instance, teachers, staff, and administration work closely hand in hand to provide a stable environment that in return creates a better learning experience. In general, the overall advantage of Reggio Emilia training is that it offers children an atmosphere that facilitates not just children's academic development but also emotional, communicative skill, and physical development as a whole.

Even though Bank street approach began as an educational experiment in 1918, its philosophies have remained relevant to date. One of the main benefits of this approach is that children gain knowledge about what they learn through practical experience. For example, they are encouraged to express themselves freely in painting and drawing. The approach also exposes learners directly to their environment through field trips and visiting interesting places (Bertram, 2002). As a result, this form of learning allows the children to acquire hands-on experience in the real world. According to 
Cullen (2006), knowledge acquired through practical experience lasts longer in the memory of a child as compared to theoretical knowledge. Therefore, tutors and stakeholders consider children who learn under this programme as having memory based on experience/ observation compared to those who taught themselves theoretically.

The high scope philosophy endeavors to instil values in children that would help them to become responsible people in the society. To achieve this objective, children go through routine work. According to Cullen (2006), the best way to master any aspect of learning is to repeat similar work frequently until it becomes a part of you. Beside routine work, tutors teach learners practically by being allowing them to interact with the environment.

This interaction also serves a very critical role in ensuring that the children learn from experience. Children learn what they see; therefore, the fact that the classrooms where this philosophy applies are well-organized means that this practice offers an excellent lesson. Therefore, pre-school implies that this practice offers a good lesson. Moreover, pre-school children in high scope schools are more organized, responsible and well time planners (Wood, 1998). These virtues enable such children to become self-directed thus better learners.

The Parents' Co-operation approach may seem involving, but it is a very helpful strategy for children. The method requires that both parents and teachers play an active role in the entire learning process of their children. The schools where this approach is used, the administration allows parents to learn together with the children. The approach has benefits such as teaching children co-operative skills. These values enable children to learn from others and share experience (Edd, 2004).) Additionally, it teaches children on how to appreciate others and getting along with them despite their background. The other benefits children get from this philosophy is that it equips them with conflict resolution skills. These skills come handy in all the interactions they will have later in the schooling lives.

\section{Methodology}

The study uses a quantitative approach to analyzing the different approaches to teaching preschoolers. The researcher selected the respondents for the study using simple random sampling in various schools from all over Pakistan through some selected schools. Fifty respondents were used in the survey who were children aged between three to six years and teachers. The children were from both nursery and pre-primary school level. For the purpose of this study, the selected teachers have more than were ten years teaching experience having different level of qualifications in nursery and preprimary level. Teachers had different levels of education. Some had a degree while others had a college diploma in teaching preschoolers. The data collection method was in the form of questionnaires that contained research questions in details. The researcher had to explain to the children the questions before filling the questionnaires. The guardians and parents guided the children in answering most of the questions. The teachers too responded to queries about teaching approaches based on their assessment of the level of understanding of the children when they apply each method. The reason for selecting teachers with over ten years of experience is that they are knowledgeable in all teaching approaches and they can advise on the best approach based on their assessment over the years (Colgrane, 2012).

\section{Data Presentation}

The summary of the results from the questionnaires as per the order below:

\section{Question 1}

Most common method used in teaching preschoolers in Pakistan

Table 1

\begin{tabular}{lll}
\hline Method/Approach & Frequency & Performance (\%) \\
\hline Montessori & 5 & 10 \\
Reggio Emilia & 12 & 24 \\
Waldorf & 16 & 32 \\
Bank Street & 10 & 20 \\
Traditional & 7 & 14 \\
TOTAL & 50 & 100 \\
\hline
\end{tabular}

Question 2

Which method is the most effective for teaching preschoolers? 


\begin{tabular}{|c|c|c|c|}
\hline Method/Approach & Response & Frequency & Performance \\
\hline Montessori & Very Good & 15 & 40 \\
\hline Reggio Emilia & Good & 20 & 30 \\
\hline Waldorf & Average & 10 & 20 \\
\hline Bank Street & Poor & 5 & 10 \\
\hline \multirow[t]{2}{*}{ Traditional } & Very Poor & 0 & 0 \\
\hline & & 50 & 100 \\
\hline
\end{tabular}

\section{Question 3}

Factors to consider in offering quality preschool education

\begin{tabular}{llll}
\hline Number & Factor & Frequency & Performance \\
\hline 1 & Class environment & 25 & 50 \\
2 & Child independence & 10 & 20 \\
3 & Teacher's approach & 15 & 30 \\
& & 50 & 100 \\
\hline
\end{tabular}

\section{Question 4}

How will a new integrated approach perform as compared to the other methods when used independently?

\begin{tabular}{lll}
\hline Response & Frequency & Performance \\
\hline Very good & 15 & 40 \\
Good & 20 & 30 \\
Average & 10 & 20 \\
Poor & 5 & 10 \\
Very poor & 0 & 0 \\
TOTAL & 50 & 100 \\
\hline
\end{tabular}

\section{Summary of the Findings}

The descriptive analysis of the data using SPSS are on the appendix.

An explanation of the descriptive analysis is as explained below:

\section{Research Question 1}

According to the findings, the Waldorf approach was found to be the most common method of teaching preschoolers with a membership of $32 \%$. The Montessori approach reported the least membership at $10 \%$.

\section{Research Question 2}

$40 \%$ of the respondents considered the Montessori approach as the best program. However, Reggio Emilia also proved to be quite preferred with a $30 \%$ popularity. Nevertheless, the traditional approach, which is still used in some educational institutes, was considered as the most ineffective method.

\section{Research Question 3}

According to $50 \%$ of the respondents, the classroom environment was the major determinant of the quality education. The second most important factor was the approach the teacher uses with a $30 \%$ to consideration child independence was the least determinant of quality preschool education with $10 \%$.

\section{Research Question 4}

$40 \%$ of the respondents thought that it would perform well. On the contrary, $30 \%$ thought that it would perform very well.

\section{Conclusions}

From the analysis of the different approaches used in teaching preschoolers, the study found out that the different methods or approaches used are still effective. The most common method used by many tutors is the Waldorf system. Even though Waldorf is the most common method, the respondents recognized that the Montessori approach is the best program to be applied. However, the infrastructure required to put it in practice makes it popularity less. Lastly, a high number of the respondents also think that an integrated approach would be the best to use.

\section{Recommendations}

In order to offer the best quality education to preschoolers in Pakistan, the researcher recommends the following:

* $\quad$ Sensitization of stakeholders on need to work towards an integrated approach

* Combination of the best qualities of each program to form an integrated approach

* Government of Pakistan to allocate more resources towards infrastructure required to facilitate an integrated approach to quality education at the basic level. 


\section{References}

Bartram, P. (2002). Early Years Education: An International Perspective. London: Qualifications and Curriculum Authority.

Cullen (2006). From Checklist to Narratives in Special Education. Australian Journal of Early Childhood, 26-31.

Czerwinski, S. (2007). What Factors Affect Physical Development? American Journal of Human Biology, 44-48.

Edd, W. (2004). Developing a Pedagogy of Play. Early Childhood Education: Society and Culture, 19-31.

Erikson, E. (1993). Childhood and Society. New York: W.W. Norton.

Gage, N. L. (1978). The Scientific Basis of the Art of Teaching. New York: Teachers College Press.

Kristof, N. (2006, April 30). Opening Classroom Doors. The New York Times. Retrieved December 6, 2008, from http://select. nytimes.com/2006/04/30/opinion/30kristof.html

Lore, B. (2002). Young Children Learning Cultures: Starting School Buckingham: Open University Press.

Matt, F. (2004). Supporting Conceptual consciousness or Learning in a Roundabout. International Journal of Science Education.

Moll (2005). Theorizing Practices in Households, Communities and Classrooms: New Jersey: Erbium Associates.

Morrison, C. (1998). Assessing Learning in Early Childhood: New Zealand: NZCER.

Muttock, S. (2002). Researching Effective Pedagogy in the Early Years. Department of Education and Skills, UK, Research Report RR356.

Nuttal, E. (2004). Exploring the Curriculum: Early Childhood Folio. A collection of Recent Research, 8, 16-20.

Piaget, J. (1969). Psychology of the Child. New York: Dutton \& Company.

Pianta, R., Howes, C., Burchinal, M., Bryant, D., Clifford, R., Early, D., \& Barbarin, O. (2005). Features of Pre-Kindergarten Programs, Classrooms, and Teachers: Do they Predict Observed Classroom Quality and Child-Teacher Interactions? Applied Developmental Science, 9(3), 144-159.

Sanders, W. L., \& Rivers, J. C. (1996, November). Cumulative and Residual Effects of Teachers on Future Student Academic Achievement. Knoxville: University of Tennessee Value Added Research and Assessment Centre.

Smith, B. (1980). Design for a school of pedagogy. Washington, DC: U.S. Department of Education.

Solomon, G. (1987). Product or Praxis? London: Falmer Press

Wellman, G. (1998). Handbook of Child Psychology (5th Edition, pp. 515-518). New York: John Willey

Wood, B. (1998). Constructivist or Social Constructivist? Teachers Theories of Play. Early Child Development and Care, 20-28. 